\title{
Examining Scaffolding Support in a Computer-Based Learning Environment for Elementary School Learners
}

\section{Tondeur Jo*; Devolder Anneline; van Braak Johan ${ }^{1}$}

Department of Educational Studies; Ghent University

* Research Foundation Flanders

\begin{abstract}
This study explores the use of a variety of scaffolds in the computer-based learning environment (CBLE) based on theories to promote self-regulated learning. First, general theoretical constructs underlying the CBLE are described, in which the focus lies on the concept of scaffolding. Then the interface and the content of the CBLE are illustrated. Finally, the scaffolds implemented in the CBLE are described. Results showed a high use of the scaffolds by elementary school learners. However, a decrease in scaffolding use was found over time. In addition, no differences were found between embedded and non-embedded scaffolding use. Relating these findings to the time learners spent in the CBLE, conclusions towards future designs and use of the CBLE and its scaffolds can be made.

Submitted

20 August 2015

Revised

23 March 2016

Accepted

08 April 2016

Keywords:

Sellf-regulated Learning,

Scaffolds,

CBLE,

Elementary school

learners.
\end{abstract}

\section{Suggested Citation:}

Tondeur, J., Devolder, A., \& van Braak, J. (2016). Examining Scaffolding Support in a Computer-Based Learning Environment for Elementary School Learners, International Journal of Academic Research in Education, 2(1), 24-41. DOI: 10.17985/ijare.78505

\section{INTRODUCTION}

In General, computer-based learning environments (CBLEs) refer to open-ended, student-centered learning environments (Hannafin \& Land, 1997) used to foster the learning of (challenging) topics (Lajoie \& Azevedo, 2006). These CBLEs are used to support learning goals and knowledge construction by creating environments that make it possible to represent, manipulate and explore complex topics (Land,

${ }^{1}$ Ghent University, $\underline{\text { Jo.Tondeur } @ \text { Ugent.be }}$ 
Examining Scaffolding Support ...

2000). According to Hannafin and Land (1997), environments such as these give students the ability to organize interrelated learning themes into meaningful contexts by, for instance, orienting goals or problems to be solved. Features and activities in these environments are functionally related and provide interactive, complementary activities that enable learners to address their interests and needs while questioning the information (Hannafin, \& Land, 1997). According to these authors, the conditions set in these environments enhance thinking and learning, while technology that supports the learning process.

Because of the characteristics of current CBLEs (e.g. open-ended, non-sequential information), topics that are difficult to explain or to comprehend (e.g. sciences) become more accessible. To learn effectively in today's open-ended CBLEs, pupils need to show greater skills than required in traditional learning environments (Winters, Greene, \& Costich, 2008). Learners are likely to enjoy success in these CBLEs when they are able to employ self-regulated learning (SRL) skills (Azevedo, 2008; Winters et al., 2008). SRL is defined by Pintrich (2000) as "an active, constructive process whereby learners set goals for their learning and then attempt to monitor, regulate, and control their cognition, motivation, and behavior, guided and constrained by their goals and the contextual features in the environment" (p. 453). Selfregulated learners are characterized as learners who strategically interact with tasks while being cognitively as well as metacognitively engaged and motivationally committed (Hadwin \& Winne, 2001). These learners participate in their own learning process while they monitor their performance, evaluate how this performance needs improvement and perform the necessary steps towards achievement. However, SRL requires a level of competence that is not easily reached by many pupils (Dignath, Buettner, \& Langfeldt, 2008).

Scaffolding was originally defined as "an adult controlling those elements of the task that are essentially beyond the learner's capacity, thus permitting him to concentrate upon and complete only those elements that are within his range of competence" (Wood, Bruner, \& Ross, 1978, p. 9). In this traditional description of scaffolding, the interaction between an adult (expert) and child (novice) was central to the effort of task completion (Sharma \& Hannafin, 2007). Later, the notion of scaffolding was linked to Vygotsky's 'zone of proximal development' (ZPD) in the sense that instruction in the ZPD was viewed as scaffolding for a novice learner so that he or she would become able to perform a task or achieve a goal that could not have been achieved without this support (Pea, 2004). Regarding the metaphor that underlies this conceptualization of scaffolding, the support provided to pupils is temporary and must be removed when no longer needed (Lajoie, 2005). In this sense, scaffolding is a form of calibrated support, i.e. support that is fine-tuned on the basis of an ongoing diagnosis of the child's knowledge and skills (Puntambekar \& Hubscher, 2005). With this kind of support, the learner comes to internalize the learning processes until the support can be decreased or even be removed completely (Pea, 2004).

The concept of scaffolding becomes less clear when it is extended to the context of learning with CBLEs. In this context, scaffolding refers to technology tools, resources and environments in the form of 
Tondeur, J., Devolder, A., \& van Braak, J.

strategies, tools and guides (Azevedo, 2005). Researchers emphasize the importance of redefining scaffolding in the new contexts of learning, such as learning in CBLEs, in order to come to a common understanding of how to use scaffolds to support and optimize learning (Puntambekar \& Hubscher, 2005). Of course, this use of scaffolds depends upon the type of delivery in which scaffolds are presented. A distinction can be made between embedded and non-embedded scaffolds. If the scaffolds are embedded in the CBLE, learners are obliged to use them or to at least see them (Narciss, Proske, \& Koerndle, 2007). Non-embedded scaffolds are those where the use depends on the personal initiative of the learners (Narciss et al., 2007). According to Puntambekar and Hubscher (2005), when tools are built so that learners can decide upon the support that is used, understanding of how students use these features is crucial, along with gaining insight on the issue of non-use (Clarebout \& Elen, 2006; Puntambekar \& Hubscher, 2005). An important function, therefore, has been put in the hands of design studies that collect data and record changes over time (Puntambekar \& Hubscher, 2005).

\section{General description of the CBLE watweetjeoverevolutie.be}

\section{Interface of the CBLE}

Central to this study is a CBLE specifically designed to examine how processes of SRL can be supported in order to increase learner achievement by providing a variety of scaffolds. When learners enter the environment, they first see a login page. Because every learner receives a personal login code, it is possible to register and analyze all the actions, personal information, scores and logs for each learner separately. When logged in, learners come to the central page that links them to six different learning modules. When a module is selected, a flash animation starts showing pictures related to evolution theory as well as daily life and animal life in general. Along with this animation, a general question is posed as an introduction to the central topic of the module.

As can be seen in Figure 1, every module consists of three main sections and a link to a post-test. This general framework is used for every module. On the left side of the screen $(A)$, the themes of each module are presented in a list. When a learner clicks on a specific theme, information appears in the middle section (B). In this section, pieces of text are presented, along with videos, pictures and animations. In the right section (C) are some of the scaffolding tools. These tools, along with the other scaffolds, are described in the following section of this study. For each learner, a dictionary as well as a timeline is available. 


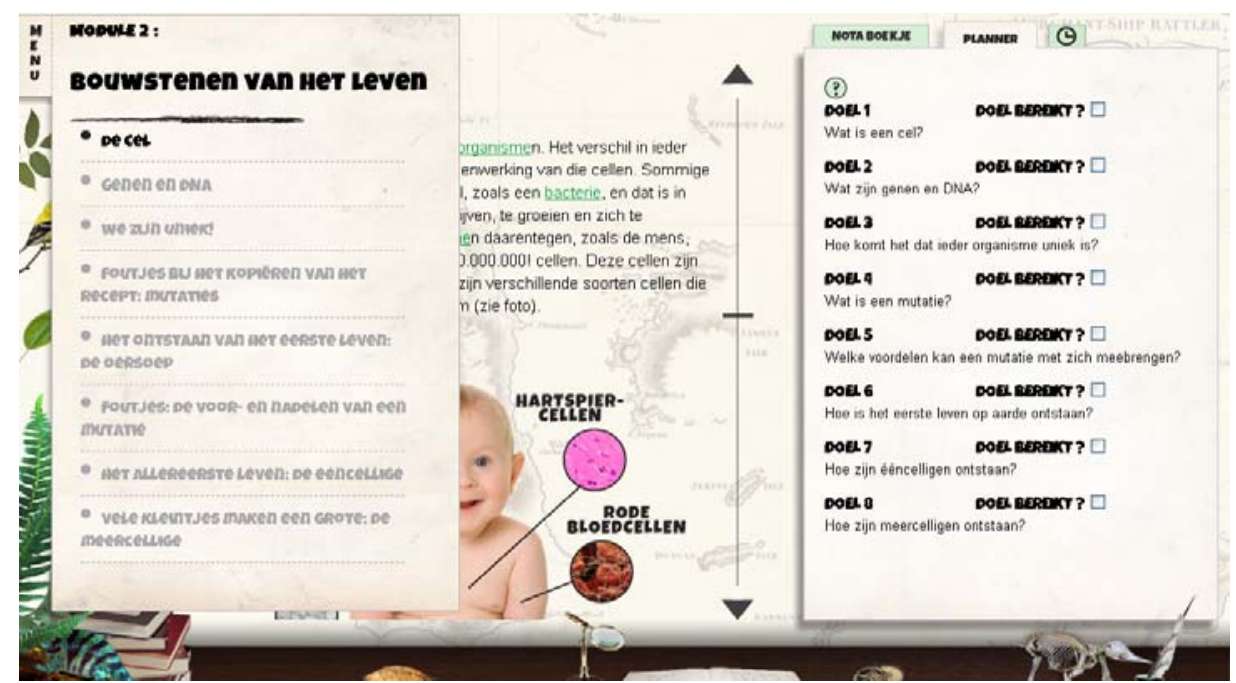

Figure 1: Sections of the CBLE

When pupils have finished a learning module, they have to complete a post-test. The content of the posttest relates to the content of the just-completed module. Declarative as well as procedural knowledge is gauged in the post-test. The structure of the post-test is a combination of multiple choice questions (e.g.: 'the red throat pouch of a frigatebird... a: does not have a function in nature; b: helps the young to find their parents more easily; c: is identical in color for all the frigatebirds; and d: is an important characteristic to attract females) and one essay question (e.g.: 'Choose a pet an give an example of a way in which that pet has adapted positively to its environment. Explain why the adaptation is positive for this animal'). This essay question is formulated to examine learners' knowledge. From the moment learners have filled in the post-test, results on the multiple choice questions are automatically generated by the system: learners can see their score as a basic form of feedback. The learning time in each module is limited to 40 minutes. Learners decide for themselves when they are finished with the module and proceed to the post-test. However, after 35 minutes learners receive a notice that they have to go to the post-test within five minutes.

Central theme of the CBLE: evolution theory

The central theme of the CBLE is evolution theory, but the interface can be adapted for any course or learning material. The subject of evolution theory as a higher-order domain was selected for a number of reasons. First, CBLEs are seen as especially useful when enhancing pupils' understanding of complex topics like sciences (Azevedo, 2005). According to this author, learning these complex topics appears challenging, especially for novices, because the content is multilayered and entails nonlinear and recursive relationships.

Table 1: Overview of the content of the modules 
Tondeur, J., Devolder, A., \& van Braak, J.

\begin{tabular}{lllll}
\hline & Central theme & Text & Video & Pictures/ \\
& & & & Animations \\
\hline Module 1 & Evolution theory & 1815 & $2^{\prime} 20^{\prime \prime}$ & 9 \\
Module 2 & Origination of life & 1396 & $0^{\prime} 50^{\prime \prime}$ & 9 \\
Module 3 & Origination of species & 1952 & - & 13 \\
Module 4 & Origination from first fish till humans & 1768 & $5^{\prime} 10^{\prime \prime}$ & 9 \\
Module 5 & Proof of evolution & & & 17 \\
Module 6 & Humans \& the evolution & 1309 & - & 12 \\
\hline
\end{tabular}

The scaffolds integrated in the CBLE

Four different types of scaffolds are integrated into the CBLE watweetjeoverevolutie.be. These scaffolds are selected on the basis of a review study focusing on effective scaffolds in supporting processes of SRL when learning sciences in CBLEs (Devolder, Van Braak, \& Tondeur, 2012). First, a note maker is available in the form of a notebook, allowing learners to note whatever they want. Notes can be formatted in italics, color, bold or underline. In addition, lines and arrows can be drawn to schematize the notes. Further, notes can be saved and retrieved when working in other modules. It is theorized that this note maker supports SRL in different ways. First, it can help regulating processes in the phase of task definition and planning for the area of motivation as well as control processes in the cognitive area (Butler \& Lumpe, 2008). Also, the note maker might support processes of SRL in the monitoring and control phases (Zydney, 2008) as well as the reflection and reaction phase (Manlove, Lazonder, \& De Jong, 2007) when used in combination with other scaffolds such as question prompts.

The second scaffold integrated in the CBLE is the planner. This tool consists of specific goals learners need to pursue, along with a check-off box corresponding to each goal. Learners can change the sequence of these goals. These goals are formulated as questions in order to support - rather than steer - the learners. When a learner thinks a goal is reached, he or she can check off the corresponding box. Proske, Narciss, and Körndle (2011) suggest that a learning plan tool whereby learners can determine the sequence of the prescribed learning goals and evaluate their progress in the light of these goals might support pupils in the forethought phase (i.e. task definition), performance phase (i.e. control) and selfreflection phase of SRL.

Third, since learners follow their own learning plan in this CBLE, a timer is integrated in the form of a clock that counts down from 40 minutes. The timer informs the learners how much time they have already spent on a certain topic and how much time they have left to achieve the goals.

Finally, also integrated in the CBLE are guiding question prompts. The question prompts pop up on the screen according to a predetermined schedule. This means that after being in the module for five 
minutes, for instance, a first prompt appears on screen, followed by another prompt 10 minutes later. Two of these prompts refer to the use of the note maker (e.g.: 'Do you find the tool that can help you to process all the information?'; 'Did you save all the information that you believed to be important?'). One prompt refers to the use of the timer (e.g.: 'Do you have sufficient time to answer all the questions?') and the latter two prompts relate to the use of the planner (e.g.: 'There is a great deal of information in this module to be explored, how will you organize this?'; 'Will you be able to achieve your planned goals?'). In a review study, authors (2012) show that question prompts are especially effective in the cognitive area of self-regulation. Davis and Linn (2000) also found effective support of these scaffolds when it comes to monitoring behaviour, planning and task-defining processes and reflection. The question prompts are developed as open questions so these would serve as indirect support in function of the use of the other scaffolds. Moreover, by providing these as questions, SRL processes are rather supported than interfered (Proske, Narciss, \& Korndle, 2010). Although these question prompts can be effective at a high rate, research has shown that they can also interrupt the learning processes (Manlove et al., 2007). As suggested by these authors, the number of question prompts is limited.

In the first part (modules one to four) of the intervention in this study, scaffolds are presented embedded, which means, as described above, that learners are obliged to at least see them (Proske et al., 2010). The embeddedness of the scaffolds takes shape in the function of the guiding question prompts. At pre-programmed times, these pop up on the screen, and when these are closed by the learner, the scaffold which is referred to in the content of that particular prompt is opened automatically. For instance, when learners start in the environment, two minutes later, a guiding question prompt pops up on the screen referring to the use of the planner. Then when closed, the planner is opened by the system to support learners in the initial planning processes. In the fifth module of this study, a group of learners is placed in a non-embedded condition. This means that the guiding questions do not pop up on the screen at pre-programmed times. In this condition, the use of the guiding question prompts, still in conjunction with the opening of the related scaffold, will depend on learners' initiative. When a learner clicks on the tab 'hint', then a prompt pops up on the screen. The prompts can be opened by the learner, and the five prompts, as described above, then repetitively reappear. For both conditions, the note maker, timer and planner are also available to be used at any time.

\section{Purpose of the study}

As stated in the literature section above, scaffolds are integrated in current CBLEs to support learning processes related to SRL. However, there seem to be conceptual as well as usability problems with regard to the aspect of scaffolding when learning in CBLEs. Successful use, over-use, underuse and non-use of scaffolds have been reported in literature and this particularly at the level of high school learners or higher education (e.g. Azevedo, 2008; Clarebout \& Elen, 2009; Proske et al., 2011). At the level of elementary school learners, little research was carried out in this field (Authors, 2012). Nevertheless, in 
Tondeur, J., Devolder, A., \& van Braak, J.

current CBLEs, the learning process is dominantly being placed in the hands of the learner him/herself, so it is important to make clear how learners use the scaffolds to support or even optimize the learning process in function of knowledge gain. Hence, in this study, it is examined at what level elementary school learners use the scaffolds integrated in the CBLE.

Additionally, it is expected in these CBLEs that learners are capable of deciding on the amount of support they need and that this capability increases along with the acquirement of SRL skills (Jackson, Krajcik, \& Soloway, 1998; Puntambekar et al., 2005). Since elementary school learners have insufficient SRL skills in general (Dignath et al., 2008), it is then the question if their scaffolding use changes over time and as such reflects possible acquirement of SRL skills.

Following the original description of scaffolding, the final destination of the scaffold itself is removal because when removal of the support is possible, learners have internalized the processes (Pea, 2004). In this study, a first gradation of this removal is studied by varying the presentation of the scaffolds from embedded towards non-embedded. Following research questions are examined:

- At what level do elementary school learners use these scaffolds integrated in the CBLE?

- To what extent does this use change over time?

- How does the use change if scaffolds are presented non-embedded?

\section{METHOD}

\section{Procedure}

\section{Antecedent developments: alpha \& beta testing}

After the technical development of the CBLE, the environment was extensively tested. In a first study, alpha testing was applied, which refers to testing the usability, comprehensibility, lay-out and general technical features of the environment (McKenney \& Reeves, 2012). Therefore, a pilot study of six 10-12 year olds was set up whereby these learners worked in the environment for 50 minutes. Each learner independently went through two modules. Afterwards, learners filled in a questionnaire gauging at pupils' perceptions about the design and development. The results of this questionnaire were then discussed in a semi-structured interview. This first evaluative phase confirmed that the general lay-out and design features did not disturb the learning process and that the level of the content of the different modules was age-appropriate. On the other hand, technical errors were found, such as the question prompts that did not pop up at the prescribed points of time.

In a second pilot study, beta testing was conducted in seven classes (147 pupils; three schools) to test the use of the adapted environment in the context of the schools and this on a broad scale (McKenney \& Reeves, 2012). First, it was examined if the research protocol, which can be seen as the detailed scenario of the full intervention, fitted the classroom context. As such, it was for instance questioned if its general 
Examining Scaffolding Support ...

predefined time format was correct and if the pre-task training proceeded within this time lapse as foreseen. This training started from a class discussion about how to solve a general open task using the different learning steps presented by the Meichenbaum bears: 1 . What do I have to do?; 2 . How will I do it?; 3. Doing it; 4 . I am checking my work, have I done it right? For each step, it was discussed how a task could be handled best. In light of this conversation, the environment was then presented and the different learning steps were repeated and extrapolated towards learning with the scaffolds in the environment. Following the protocol, after this training, learners then filled in the pre-test and subsequently went through two modules. Learners finished each module by filling in the post-test. Results of this beta evaluation were for instance that the timing of the introductory lesson was sufficient though the exact learning time in the modules could be decreased since learners finished earlier than expected.

\section{Intervention: gamma testing}

In this phase, gamma testing is fulfilled, examining if the environment meets its goal, such as do learners use the scaffolds as intended (McKenney \& Reeves, 2012)? In this study, six elementary schools participated, of which one school participated with two classes. This accounted for 126 pupils of which 67 girls and 59 boys, all aged between 11 and 13. Following the protocol, the first session entailed the pretask training since research has repeatedly shown that this positively affects SRL behaviors (Bernacki, Aguilar, \& Byrnes, 2011). In this training session, learners were taught how the scaffolds relate to SRL as well as how the CBLE and scaffolds function. After this training session of 15 minutes given by the researcher, learners were given the ability to work in the environment. For this practice session, a module was developed focusing on a different content area (the Middle Ages). After 10 minutes, learners had to leave the environment and had to go to the pre-test. Learners were able to finish this pre-test in maximum 45 minutes. In the second session, which was planned a week later, learners logged in into the environment, went through the first module and completed this module by filling in the post-test. In the consecutive weeks, learners finished the three following modules.

At the start of the fifth module, learners were divided in two groups. Post-test scores of the first three modules were used to do this in a stratified manner. This resulted in two equal groups of 63 learners each, representing a non-embedded and embedded scaffolding condition. The embedded scaffolding group learned in the same manner as in the previous weeks: the guiding question prompts were available to them through pop-ups presented at a fixed point in time whereby the scaffolds relating to these prompts also automatically opened. The non-embedded scaffolding group did not receive these prompts automatically any more, instead learners needed to open these themselves. As such, the purpose of this division was to examine if learners who have access to the scaffolds more easily or who are stimulated more to use the scaffolds (embedded scaffolding group) use these differently in comparison to learners who need to show more initiative to use the scaffolds (non-embedded scaffolding group). In this study, results of the sixth module are not presented due to technical difficulties. 
Tondeur, J., Devolder, A., \& van Braak, J.

Measures

Following Hadwin and Winne's (2001) advice to realize the potential of current CBLEs, e.g., to measure learning processes in action, this CBLE makes use of trace methodologies in the form of log-files. Using trace methodologies like log-files, the quality of learners' learning can be measured by capturing the sequence and duration of these processes. Moreover, log-files could be seen as accurate data collection formats (Greene \& Azevedo, 2007). They are an objectification of ongoing SRL processes that bring the dynamic character of SRL in account (Hadwin \& Winne, 2001). In this CBLE, log-files are used to measure the general learning time and frequency of every learning activity. This means that every time a learner clicks on an item, opens an item or writes something in the CBLE, this will be registered for each learner individually. Using these methodologies enables to "characterize temporarily unfolding patterns of engagement with tasks in terms of the tactics and strategies that constitute SRL and compare patterns over time to reflect regulation per se" (Winne \& Perry, 2001, p. 563).

Table 2 presents at what level each scaffold was measured via the log-files and how these measures were labeled. With regard to the use of the note maker, it was first measured if learners used this scaffold, second, how many times learners used this scaffold, third, at what level they used this and fourth, with what intensity. The level of the note maker is determined on the use of a $3 \times 4$ score rubric. A researcher and a science teacher each scored the note books separately and then discussed discrepancies in scores until $100 \%$ agreement was reached. Scores varied from one to twelve. The first level of scores represents notes with plain text that are copy-pasted from the CBLE (1), that are copy-pasted and supplemented with own formulations (2) and that are exclusively own word formulations. The second level entails this same triple classification but notes represent text with color additions (score 4-6). This also accounts for the third level, whereby structure is added towards the notes for instance by applying numbering (score 7-9), and for the fourth level whereby even schemes are added for instance by using arrows (score 1012). The intensity of the note maker is then represented by the general amount of characters learners have written in the note maker.

Subsequently, the planner is first represented by a dichotomous variable, used or not-used. For the check-boxes and the goals, a dichotomous variable as such is also created. At continuous level, again the general use was represented for the planner ('use of planner'), the goals ('replace goals') and the checkboxes ('use of check-boxes'). Moreover, since the use of the planner is related to the replaceable goals and the check-boxes (e.g., the planner needs to be opened first before check-boxes can be used), variables at nominal level are constructed that represent the possible use of this tool as a whole. First, learners can use the planner without changing the goals or checking off the boxes (level 1), it can also be that the planner is opened to change the goals only (level 2) or to check off only (level 3) or for both (level 4). Next to these scaffolds, the amount of time learners spent in the CBLE was registered and labeled as 'time', the use of the timer was registered ('timer') and the number of times learners opened the timer 
Examining Scaffolding Support ...

('use of timer'). Finally, the guiding question prompts were represented in function of the action that is sequenced when the prompt is closed.

Table 2: Measures of the scaffolds

\begin{tabular}{|c|c|c|c|}
\hline Scaffold & Measure & Description & Label \\
\hline \multirow[t]{4}{*}{ Note maker } & Dichotomous & Is the note maker used? Yes or No & Note Maker \\
\hline & Continuous & Number of characters written by the learner & Characters \\
\hline & Continuous & How many times is the note maker opened? & Use of note maker \\
\hline & Continuous & At what level is the note maker used? & Level of notes \\
\hline \multirow[t]{11}{*}{ Planner } & Dichotomous & Is the planner used? Yes or No & Opening planner \\
\hline & Dichotomous & Are the goals planned? Yes or No & Planning goals \\
\hline & Dichotomous & Are the check-off boxes used? Yes or No & Check-off boxes \\
\hline & Continuous & How many times is the planner opened? & Use of planner \\
\hline & Continuous & How many goals are planned? & Replace goals \\
\hline & Continuous & How many times are the check-off boxes used? & Use of Check-off \\
\hline & & & boxes \\
\hline & Dichotomous & \multicolumn{2}{|c|}{$\begin{array}{l}\text { Planner used without replacing goals or without Planner Level } 1 \\
\text { using the check-boxes }\end{array}$} \\
\hline & Dichotomous & \multicolumn{2}{|c|}{$\begin{array}{l}\text { Planner used to replace the goals without using Planner Level } 2 \\
\text { the check-boxes }\end{array}$} \\
\hline & Dichotomous & \multicolumn{2}{|c|}{$\begin{array}{l}\text { Planner used to use the check-boxes without Planner level } 3 \\
\text { changing the goals }\end{array}$} \\
\hline & Dichotomous & \multicolumn{2}{|c|}{$\begin{array}{l}\text { Planner used to replace the goals and to use the Planner level } 4 \\
\text { check-boxes }\end{array}$} \\
\hline Timer & Dichotomous & Is the scaffold used: Yes or No? & Timer \\
\hline & Continuous & How many times is the timer opened? & Use of timer \\
\hline $\begin{array}{l}\text { Question } \\
\text { prompts }\end{array}$ & Dichotomous & \multicolumn{2}{|c|}{$\begin{array}{l}\text { Scaffold } x \text { used if guideline refers to scaffold } x \text { : Yes Question prompts } \\
\text { or No }\end{array}$} \\
\hline
\end{tabular}


Tondeur, J., Devolder, A., \& van Braak, J.

\section{FINDINGS}

\subsection{General use: Modules 1-4}

With regard to the use of the scaffolds in modules one till four, in general, high scaffold use was found. Graph 1 presents the percentages of the scaffold use by the learners (dichotomous - yes or no). Some scaffolds were used by a high amount of learners, with for example the planner being opened by all learners in three modules. The use of the planner seems to relate especially to the use of the check-off boxes. Thereby, minimum $81 \%$ of the learners used the check-off boxes when learning in a module. Minimum 21\% of the learners planned their goals when learning in a module. With regard to the note maker, more than $50 \%$ of the learners used this scaffold during all modules. In the first, second and third module, this percentage exceeds $70 \%$, though a decrease in use is strongly visible especially in the fourth module (51.6\%). The timer was used by $99 \%$ of the learners in the first module, with a slight decrease to $82 \%$ in the second module. When the use of the scaffolds by the learners is examined over the four modules, the decrease of learners using the note maker and the goal planner is most prevalent.

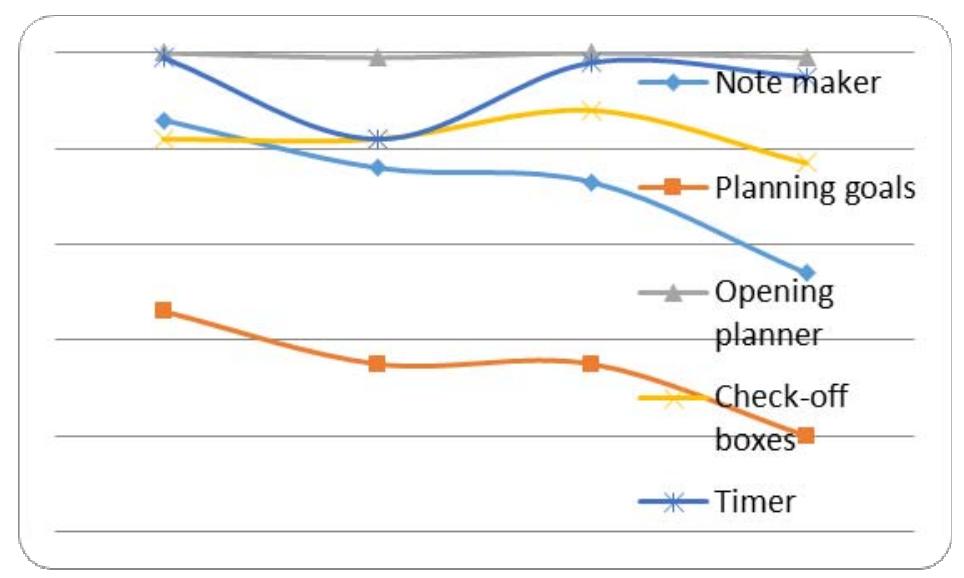

Graph 1: Average percentage of scaffold use per module

Table 3 presents the use of each scaffold during the modules. One-way repeated measures ANOVA's were conducted to compare scaffold use over time. As can be seen in Table 3, learners open the note maker significantly more in the first module in comparison to the other modules. The number of times the note maker is opened in the fourth module is also significantly lower than in the second and third module. The level of the notes in the first module is significantly higher in comparison to the other modules. In the first module, learners on average are at a level whereby they combine the use of text with colors applied to text formulated with their own words or copy-paste. Despite these differences, the amount of characters stays equal throughout the four modules.

With regard to the opening of the planner, learners opened this scaffolds significantly less in the last module (from 8.74 to 5.96). This also accounts for the amount of goals that were rescheduled in the 


\section{Examining Scaffolding Support ...}

fourth module: a decrease was found for this module in comparison to the first module (from $28 \%$ of the goals to $11 \%)$. However, this decrease does not account for the use of the check-off boxes. Over time, a significant increase could be found but at the fourth module, this stagnates. These changes can also be found when focusing on the levels of use of the planner: whereas for the first module, $40 \%$ of the learners use the planner to replace the goals as well as to use the check-boxes (level four), at the fourth module, $20 \%$ of the learners apply this type of use. In the fourth module, learners using the planner at the third level then again increase by almost $20 \%$. At levels one and two, $6 \%$ is respectively increased or decreased.

The opening of the timer is comparable to the opening of the planner: on average, the learners opened the timer significantly more in the first module whereas a significant decrease could be found in the last module (from 9.60 to 4.45). Subsequently, learners spent most time in the first module. Their activity level (time learners spend) increased again after the second and third module. Results of the question prompts are not reported since the time logs showed that almost all learners (> 90\%) closed the prompt within one second. This indicates that learners insufficiently read the prompts as this demands at least multiple seconds.

Table 3: Descriptive statistics for learners' time spent and amount of scaffold use during each module $(n=126)$

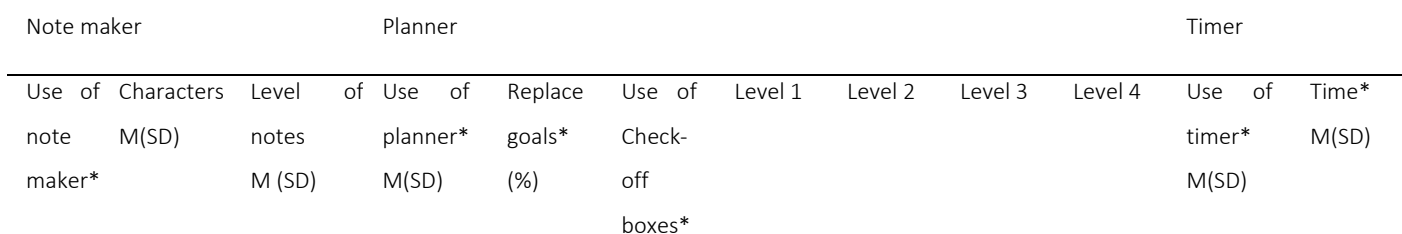

\begin{tabular}{|c|c|c|c|c|c|c|c|c|c|c|c|c|c|}
\hline & & & & & & $\begin{array}{l}\text { boxe } \\
\text { (\%) }\end{array}$ & & & & & & & \\
\hline \multirow[t]{3}{*}{ Module 1} & 10.27 & 703.84 & 5.19 & 8.94 & $28>4$ & 53 & $<$ & .12 & .07 & .42 & .40 & 9.60 & 29.86 \\
\hline & $(6.03)$ & $(845.33)$ & $(2.32)$ & (9.59) & & 2,3 & & & & & & $>2,3,4$ & $>2,3,4$ \\
\hline & $>2,3,4$ & & $>2,3,4$ & & & & & & & & & (10.41) & $(6.00)$ \\
\hline \multirow[t]{3}{*}{ Module 2} & 8.25 & 861.45 & 4.55 & 7.11 & 25 & 67 & & .13 & .04 & .49 & .32 & 5.70 & 25.50 \\
\hline & $(4.56)$ & $(1385.61)$ & $(2.34)$ & $(4.60)$ & & & & & & & & $(4.12)$ & (5.97) \\
\hline & $>4$ & & & & & & & & & & & & \\
\hline \multirow[t]{3}{*}{ Module 3} & 8.71 & 828.39 & 4.71 & 6.79 & 19 & 68 & & .12 & .00 & .53 & .35 & 5.94 & 25.40 \\
\hline & $(6.93)$ & (1905.29) & $(2.57)$ & $(4.10)$ & & & & & & & & $(5.48)$ & (5.92) \\
\hline & $>4$ & & & & & & & & & & & & \\
\hline \multirow[t]{3}{*}{ Module 4} & 5.50 & 838.58 & 4.27 & 5.78 & 11 & 64 & & .18 & .01 & .61 & .20 & 4.45 & 26.98 \\
\hline & $(3.66)$ & (1774.74) & $(2.63)$ & $(2.92)$ & & & & & & & & $<2,3$ & $>2,3$ \\
\hline & & & & $<1,2,3$ & & & & & & & & $(3.10)$ & (4.84) \\
\hline
\end{tabular}

$*: p<.05$

Note: $z><x, y$ : Post-hoc pairwise comparisons of the estimated marginal means show a significant difference of $z$ in comparison to $x$ and $y 1,2,3,4$ refer to the four different modules

Embedded vs. non-embedded use 
Tondeur, J., Devolder, A., \& van Braak, J.

Before the start of the fifth module, students were divided into an embedded group and a nonembedded group. As can be seen in Table 4, the percentage of students using the scaffolds varies little over both groups. Only a small difference in use was found in the number of students using the check-off boxes: $89 \%$ of the students in the embedded group used the check-off boxes whereas $67 \%$ of the students in the non-embedded group made use of the check-off boxes. Chi-square tests for independence (with Yates Continuity Correction) indicated no significant association between condition and scaffolding use.

Table 4: Descriptive statistics of Module $5(n=126)$

\begin{tabular}{llllll}
\hline & Note maker & Planning goals & \multicolumn{2}{c}{ Check-off boxes } & Timer \\
& $\%$ & $\%$ & $\%$ & $\%$ & Opening Planner \\
& & $\%$ & 89 & 89 & 100 \\
\hline Embedded & 60 & 16 & 67 & 84 & 95 \\
\hline
\end{tabular}

When the average use of each scaffold is examined between the two conditions as presented in Table 5, extending an independent-samples t-test, again, no significant differences were found.

Table 5: Descriptive statistics for time spent and amount of scaffolding use for Module 5 ( $n=126)$

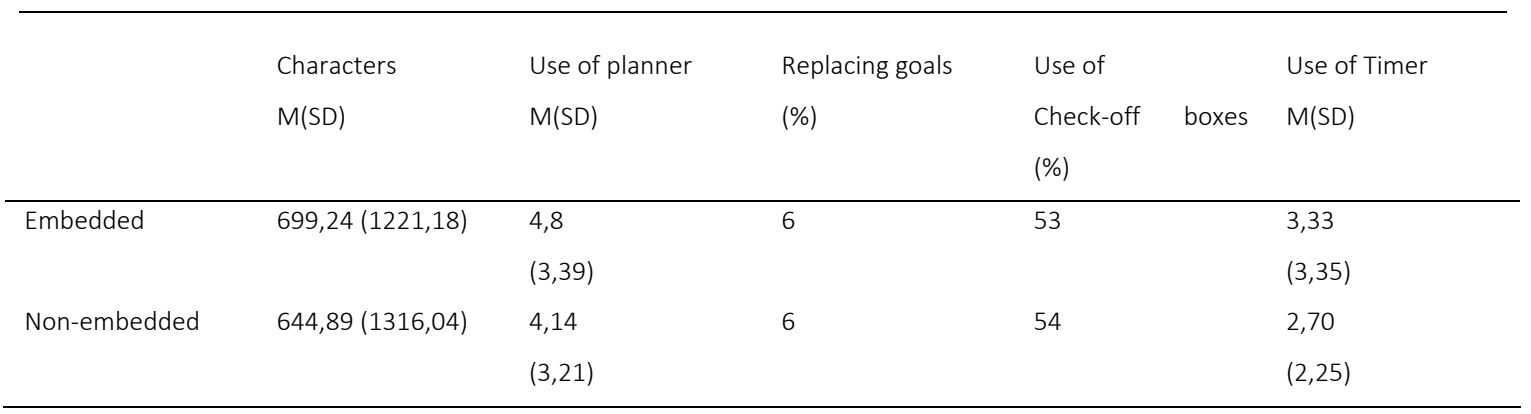

\section{DISCUSSION \& CONCLUSION}

In this study, it was examined if and at what level elementary school learners use the scaffolds integrated in the CBLE. Moreover, it was also examined how this use changes over time and if a difference in use could be found between an embedded and non-embedded scaffolding condition.

In this study, it can be noted that the scaffolds (e.g. timer, note maker \& planner - replacing goals) are used at a rather high level and this by a high amount of learners, especially for the first module. When one brings in mind that learners 'only' had 40 minutes to process all the information, for the first module, scaffolding actions were executed at least every two minutes. The high use of the scaffolds in the first module, in comparison to the other modules, could possibly show that learners were still exploring the environment during the first module. Prior to the learning sessions, learners received a pre-task training in order to get used to the environment. These findings might either show that more time needs to be 
spent in this pre-phase so learners are sufficiently acquainted with the use, function and potential of all scaffolds before starting the modules. It might also confirm the utility of the pre-task training in its aim, namely to skill untrained learners since these show less effective behavior, is certainly reflected in the first module (Bernacki et al., 2011).

When comparing the number of students that use the different scaffolds, the use of the goal planner is rather low in comparison to the other scaffolds. Nevertheless, when comparing these results with other studies focusing on comparable scaffolds (e.g. the learning plan tool - Proske et al., 2011), the amount of learners using the goal planner in this study is more than average. A possible explanation for the lower use of this scaffold might be found in its levels of the use. As can be seen, more than half of the learners open the planner without changing the prescribed goals (level 1 and level 3). This does not mean that learners do not use these goals; it is indeed possible that learners use the prescribed goals to organize the learning but in the prescribed sequence. As such, the goals still account as a scaffold for the learner, though no active interaction is taking place. The question remains then why learners do not make use of the freedom they receive to learn according to their own needs and motivation. Is it a lack of SRL skills assigned to this age group or is it rather the habit of learning according to a prescribed order, as happens in many regular classroom settings (Azevedo, 2008)?

When it comes to the use of the check-boxes, the opposite was found: a large amount of the learners did make use of the check-boxes. As such, learners checked off the goals they did not necessarily replace yet purposefully pursued. When it comes to use over time, little learners stop making use of the check-boxes but it is still unclear why learners do not use this scaffold in its maximum: checking off all the boxes of the prescribed goals.

Focusing on the use of the note maker, a rather large decrease in the number of users was also found between the first and the last module. Thereby, the amount of times the note maker was opened halved over time. For the level of the notes, after the first module, no significant differences were found and the amount of characters written in the note maker stayed equal throughout all modules. First, these findings might confirm that learners were indeed still rather exploring in the first module and were rather searching how they would handle the task. Secondly, this might also show that learners use the note maker equally intensive in the fourth module as in the second and third module albeit less frequent.

With regard to the timer, again a significant decrease in the amount of use was found over the different modules but not in the amount of learners using the timer: in the fourth module, still over $90 \%$ of the learners used the timer. This shows that learners purposefully want to regulate their time in function of for instance planning processes or maybe even in function of coping strategies since the restricted time might make learners more insecure. In this study, no results of the use of the question prompts were presented since time logs showed that most learners closed the question prompts before reading them. 
Tondeur, J., Devolder, A., \& van Braak, J.

When focusing on the difference in scaffolding use between the embedded and non-embedded learners, also no differences in use were found. Yet, it could have been expected that learners who need to show more initiative to use the scaffolds (non-embedded group) put less effort to use these in general comparison to the learners that have access to these scaffolds more easily. The most plausible explanation for this lack of difference is that at the fifth module, learners' experience with these scaffolds is as such that these do not have an added value for their learning process any more, especially since the experience with the embedded prompts was that they closed these as soon as possible. A lack of difference in functionality might also be the case.

As the previous discussion makes clear, an equal amount of learners keeps using the timer, planner and check-boxes over time. Less learners use the note maker but the intensity does not change and the level of use changes only after the first module. The use of the planner to replace the goals is also less used by the learners though the levels of use make clear that a sort of passive use is possible. Connecting these latter findings with the increase in time learners spent in the CBLE in the fourth module, it might be that an amount of the learners keeps putting equal effort in their general learning process throughout the four modules. If this latter is a reflection of increased SRL skills, since learners keep putting equal effort in their learning though the scaffolds are used less but maybe more purposefully or devised, needs to be made clear in future research. By relating these findings for instance with qualitative research methods like think-aloud measures, the 'why' after the use of the scaffolds might be revealed and as such, underlying learning processes might be revealed (Winne \& Perry, 2000). Moreover, by changing the nature of the guiding question prompts in this study towards non-embedded prompts, learners might experience more positive support of this scaffold. In their review study, Bernacki et al. (2011) stated that prompts might be experienced as too instructive to the learners. Providing these prompts in a way that is facilitative for processes of learners' SRL might be a solution to this problem. When changing the mode of delivery of the prompts from embedded to non-embedded, the CBLE is then replaced in the continuum of type of CBLE from a didactic as well as a facilitative environment to a more distinct facilitative environment (Bernacki et al., 2011). This might add to learner achievement in the future, since research indicates that CBLEs that rather regulate the learning instead of allowing learners to regulate reach less consistent evidence with regard to knowledge improvement (Bernacki et al., 2011).

To conclude, in this study, high scaffolding use was found when elementary school learners work in a CBLE focusing on evolution theory. Since in literature, often low or non-use was reported for middle school learners or higher education students, this study provides important information to further support elementary school learners. Though, since it was only focused upon quantitative measures of the scaffold use, no data could be provided upon how these scaffolds were qualitatively used in relation to the learning process. This makes that only observable (in) voluntary behavior is recorded (Barnard-Brak, Lan, \& Paton, 2010). Motivations, affects and cognitions to use these scaffolds are not mapped out. Moreover, the analysis of the logs show an amount of learners using the scaffolds but these do not make 
Examining Scaffolding Support ...

clear over time which learners change their use over time and especially, these do not answer the question why learners use the scaffolds. Therefore, in future research, additional methods to map out the learning processes in relation to the scaffold use need to be applied to provide research in this field with the full picture of learners' scaffolding use. As such, research may contribute to the construction of an adapted scaffolding concept in the field of learning with CBLEs (Puntambekar, \& Hubscher, 2005; Barnard-Brak et al., 2010).

\section{References}

Alters B.J. \& Alters S.M. (2001). Defending evolution - A guide to the creation/evolution controversy. Bartlett Publishers, London.

Azevedo, R. (2005). Using hypermedia as a metacognitive tool for enhancing student learning? The role of SRL. Educational Psychologist, 40, 199-209.

Azevedo, R. (2008). The role of self-regulated learning about science with hypermedia. In Recent innovations in Educational Technology that facilitates Student Learning (eds. D.H.

Robinson and G. Schraw), pp. 140. Information Age Publishing Inc., Charlotte.

Belland, B. R., Glazewski, K. D., \& Richardson, J. C. (2008) A Scaffolding Framework to Support the Construction of Evidence-Based Arguments among Middle School Students. Educational Technology Research and Development, 56, 401-422.

Bernacki, M. L., Aguilar, A. C., \& Byrnes, J. P. (2011) Self-regulated learning and technology-enhanced learning environments: An opportunity-propensity analysis. In Fostering Self-Regulated Learning through ICT (eds. G. Dettori \& D. Persico), pp. 1-26. Information Science Reference, New York.

Butler, K. A., \& Lumpe, A. (2008) Student Use of Scaffolding Software: Relationships with Motivation and Conceptual Understanding. Journal of Science Education and Technology, 17, 427-436.

Clarebout, G., \& Elen, J. (2006) Tool use in computer-based learning environments: towards a research framework. Computers in Human Behavior, 22, 389-411.

Davis, E. A., \& Linn, M. C. (2000) Scaffolding students' knowledge integration: Prompts for reflection in KIE. International Journal of Science Education, 22, 819-837.

Devolder, A., van Braak, J. \& Tondeur, J. (2012), Supporting self-regulated learning in computer-based learning environments: systematic review of effects of scaffolding in the domain of science education. Journal of Computer Assisted Learning. oi: 10.1111/j.1365-2729.2011.00476.x 
Tondeur, J., Devolder, A., \& van Braak, J.

Dignath, C., Buettner, G., \& Langfeldt, H.P. (2008) How can primary school students learn SRL strategies most effectively?: A meta-analysis on self-regulation training programmes. Educational Research Review, 3, 101-129.

Greene, J. A., \& Azevedo, R. (2007). A theoretical review of Winne and Hadwin's model of SRL: New perspectives and directions. Review of Educational Research, 77(3), 334-372.

Hadwin, A. F., \& Winne, P. H. (2001) CoNoteS2: A software tool for promoting self-regulation. Educational Research and Evaluation, 7, 313-334.

Hannafin, M.J., \& Land, S.M. (1997). The foundations and assumptions of technology-enhanced studentcentered learning environments. Instructional Science, 25, 167-22.

Hannafin, M., Land, S. M., \& Oliver, K. (1999) Open Learning environments: Foundations, methods, and models. In Instructional Design Theories and Models (ed. C.

Reigeluth), pp. 115-140. Lawrence Erlbaum Associates, Mahwah.

Jiang, L., Elen, J., \& Clarebout, G. (2009) The relationships between learner variables, tool-usage behavior and performance. Computers in Human Behavior, 25, 501-509.

Lajoie, S. P. (2005) Extending the scaffolding metaphor. Instructional Science, 33, 541-557.

Lajoie, S.P., \& Azevedo, R. (2006) Teaching and Learning in Technology-rich Environments. In Handbook of educational Psychology ( $2^{\text {nd }}$ ed.) (eds. P. Alexander \& P. Winne), pp.803-821. Erlbaum, Mahwah.

Land, S.M. (2000). Cognitive Requirements for Learning with Open-ended Learning Environments. Educational Technology Research and Development, 48(3), 61-78.

Manlove, S., Lazonder, A., \& de Jong, T. (2007) Software scaffolds to promote regulation during scientific inquiry learning. Metacognition and Learning, 2, 141-155.

McKenney, S. \& Reeves, T.C. (2012). Conducting Educational Design Research. Routledge, London \& New York.

Narciss, S., Proske, A., \& Koerndle, H. (2007). Promoting self-regulated learning in web-based learning environments. Computers in Human Behavior, 23, 1126-1144.

Pea, R. (2004) The Social and Technological Dimensions of Scaffolding and Related Theoretical Concepts for Learning, Education, and Human Activity. The Journal of the Learning Sciences, 13, 423-451.

Pintrich, P. R. (2000) The role of goal orientation in self-regulated learning. In Handbook of Self-Regulation (eds. M. Boekaerts, P. Pintrich, \& M. Zeidner), pp. 451-502. Academic Press, San Diego. 
Examining Scaffolding Support ...

Puntambekar, S., \& Hubscher, R. (2005) Tools for Scaffolding Students in a Complex Learning Environment: What Have We Gained and What Have We Missed? Educational Psychologist, 40, $1-12$.

Proske, A., Narciss, S., \& Körndle, H. (2011). Exploring the effects of an Optional Learning Plan Tool in Technology-Enhanced Learning. In Fostering Self-Regulated Learning through ICT (eds. G. Dettori \& D. Persico), pp. 315-333. Information Science Reference, New York.

Sharma, P., \& Hannafin, M. J. (2007) Scaffolding in technology-enhanced learning environments. Interactive Learning Environments, 15, 27-46.

Saye, J.W., \& Brush, T. (2002) Scaffolding critical reasoning about history and social issues in multimediasupported learning environments. Educational Technology Research and Development, 50, 7796.

Winne, P.H., \& Perry, N.E. (2001). Measuring Self-regulated Learning. In M. Boekaerts, P. Pintrich, \& M. Zeidner (Eds.), Handbook of self-regulation (pp. 531-566). San Diego, CA: Academic Press.

Winters, F., Greene, J., \& Costich, C. (2008) Self-Regulation of Learning within Computer-based Learning Environments: A Critical Analysis. Educational Psychology Review, 20, 429-444.

Wood, D., Bruner, J., \& Ross, G. (1978) The role of tutoring in problem solving. Journal of Child Psychology and Psychiatry, 17, 89-100.

Zimmerman, B.J. (2000). Attaining self-regulation: A social cognitive perspective. In M. Boekaerts, P. Pintrich, \& M. Zeidner (Eds.), Handbook of self-regulation (pp. 13-39). San Diego, CA: Academic Press.

Zydney, J.M. (2008) Cognitive tools for scaffolding students defining an ill-structured problem. Journal of Educational Computer Research, 38, 353-385. 